\title{
The Kinetics of Polyethylenimine-Mediated Transfection in Suspension Cultures of Chinese Hamster Ovary Cells
}

\author{
Martin Bertschinger - Arnaud Schertenleib • \\ Jean Cevey · David L. Hacker · Florian M. Wurm
}

Published online: 10 June 2008

(C) Humana Press 2008

\begin{abstract}
The kinetics of polyethylenimine (PEI)-mediated gene transfer at early times after transfection of Chinese hamster ovary (CHO) cell in suspension were investigated using a novel in vitro assay. Addition of an excess of competitor DNA to the culture medium at various times after the initiation of transfection inhibited further cellular uptake of PEI-DNA particles. Using this approach, a constant rate of particle uptake was observed during the first $60 \mathrm{~min}$ of transfection at a PEI:DNA ratio of 2:1 (w/w) and a cell density of $2 \times 10^{6}$ cells $/ \mathrm{ml}$ under serum-free conditions. The uptake rate declined considerably during the next $2 \mathrm{~h}$ of transfection. Both the rate and the level of PEI-DNA uptake in serum-free minimal medium were found to be dependent on the PEI-DNA ratio, the cell density at the time of transfection, and the extent of particle aggregation. These studies of the early phase of PEImediated transfection are expected to lead to further opportunities for optimization of gene transfer to suspension cultures of mammalian cells for the purpose of largescale transient recombinant protein production.
\end{abstract}

Keywords Transfection · Polyethylenimine · Plasmid DNA · Mammalian cells

\footnotetext{
M. Bertschinger - A. Schertenleib - J. Cevey ·

D. L. Hacker · F. M. Wurm ( $\square)$

Laboratory of Cellular Biotechnology, Institute of

Bioengineering, École Polytechnique Fédérale de Lausanne

(EPFL), 1015 Lausanne, Switzerland

e-mail: florian.wurm@epfl.ch

Present Address:

M. Bertschinger

Glenmark Pharmaceuticals SA, Chemin de la Combeta 5,

2300 La Chaux-de-Fonds, Switzerland
}

\section{Introduction}

Polyethylenimine (PEI) is one of the most widely used chemical agents for large-scale gene transfer into cultured mammalian cells for the transient production of recombinant proteins [1, 2]. The key steps for PEI-mediated transfection are the packaging of the plasmid DNA into compact positively charged particles that bind to the cell surface, the endocytosis of the particles and their subsequent release into the cytoplasm, and finally the movement of the particles into the nucleus where the DNA is released from PEI for engagement with the cellular transcription machinery [3-10]. Although endosomal release of PEI-DNA complexes and subsequent steps depend strictly on the chemical properties of PEI [11], other parameters of PEI-mediated transfection can be readily altered by the operator. For example, under physiological salt concentrations, PEI forms large aggregates with DNA, limiting particle uptake into cells via endocytosis [12], but the incubation time and the salt concentration of particle formation can be optimized to ameliorate this problem. In addition, the composition of the culture medium for transfection can be modified to reduce PEI-DNA aggregation. Two other parameters that affect PEI-mediated transfection are the cell density at the time of transfection and the overall charge of the PEI-DNA particles. The latter can be adjusted by simply changing the PEI:DNA ratio during particle formation [7]. In short, there are several factors that need to be carefully evaluated to maximize PEI-mediated DNA delivery and transient recombinant protein production for any given cell line.

Here the kinetics of PEI-DNA uptake were investigated in order to further optimize PEI-mediated transfection in suspension cultures of mammalian cells. For this purpose, a PEI-DNA uptake assay was developed to rapidly assess the 
effects of several operator-controlled parameters using enhanced green fluorescent protein (GFP) as a reporter. With the addition of an excess of competitor DNA to the culture medium after the initiation of transfection, the uptake of PEI-DNA particles was inhibited. With this approach, several factors affecting the kinetics of particle uptake were investigated in suspension cultures of Chinese hamster ovary $(\mathrm{CHO})$ cells, one of the most commonly used mammalian hosts for large-scale transient protein production [13]. The PEI:DNA ratio, the cell density at the time of transfection, and the conditions of particle formation were all found to influence both the kinetics and extent of PEI-DNA uptake at early times of transfection.

\section{Materials and Methods}

\section{Plasmid DNA}

pEGFP-N1 was purchased from Clontech (Palo Alto, CA, USA). Plasmid DNA was purified on a Nucleobond AX anion exchange column (Macherey-Nagel, Düren, Germany) according to the manufacturer's instructions and stored at $1 \mathrm{mg} / \mathrm{ml}$ in TE (10 mM Tris- $\mathrm{HCl}(\mathrm{pH} 7.4)$ and $1 \mathrm{mM}$ EDTA (pH 8.0)). The quality of the plasmid DNA was determined using a PEI-based precipitation assay as described previously [14].

\section{Cells}

Suspension-adapted CHO DG44 cells (a dihydrofolate reductase-deficient mutant) were routinely grown in 250$\mathrm{ml}$ square-shaped glass bottles (Schott Glass, Mainz, Germany). The cells were cultivated in ProCHO5 medium (Lonza Verviers, Verviers, Belgium) with $0.68 \mathrm{mg} / \mathrm{l}$ hypoxanthine, $0.194 \mathrm{mg} / \mathrm{l}$ thymidine, and $4 \mathrm{mM}$ glutamine (Sigma-Aldrich, St. Louis, MO, USA) at $37^{\circ} \mathrm{C}$ in $5 \% \mathrm{CO}_{2}$ and $95 \%$ humidity with orbital shaking at $110 \mathrm{rpm}$ as previously described [15]. Cell viability was assessed by the Trypan blue exclusion method. Packed cell volume (PCV) was determined using VoluPAC ${ }^{\mathrm{TM}}$ tubes (Sartorius AG, Göttingen, Germany) as previously described [16].

\section{Transfection}

Unless otherwise indicated, the cells were transfected in RPMI 1640 containing $25 \mathrm{mM}$ Hepes (pH 7.1) at a PEI:DNA ratio of $2: 1$ (w/w) with a mixture of pEGFP-N1 and salmon sperm DNA at a mass ratio of 2:98. Linear 25-kDa PEI (Polysciences Europe, Eppelheim, Germany) was prepared in water at a concentration of $1 \mathrm{mg} / \mathrm{ml}$ as described [17]. The cells were seeded in 12-well plates in $1 \mathrm{ml}$ of RPMI 1640 at a cell density of $2 \times 10^{6}$ cells $/ \mathrm{ml}$.
For each transfection in a single well, $2.5 \mu \mathrm{g}$ of DNA and $5.0 \mu \mathrm{g}$ of PEI (Polysciences, Eppenheim, Germany) were each added separately to $50 \mu \mathrm{l}$ of $150 \mathrm{mM} \mathrm{NaCl}$. Prior to transfection, the $\mathrm{PEI} / \mathrm{NaCl}$ solution was added to the DNA/ $\mathrm{NaCl}$ solution and allowed to stand at room temperature for 10 min before addition to the culture. After transfection the plates were incubated at $37^{\circ} \mathrm{C}$ on an orbital shaker with agitation at $180 \mathrm{rpm}$ in the presence of $5 \% \mathrm{CO}_{2}$ and $85 \%$ humidity [17]. At $3 \mathrm{~h}$ post-transfection, one volume of ProCHO5 with supplements as described above was added to each well, and the incubation was continued as before. For studies of the kinetics of PEI-DNA particle uptake, salmon sperm DNA was added in a threefold excess to PEI (w/w) at various times after transfection as indicated.

\section{GFP Quantification}

Transfected cells (1-2 ml) were lysed in a 12-well plate by addition of 0.5 volumes of phosphate buffered saline (PBS) containing $1 \%$ Triton $\mathrm{X}-100$. After $1 \mathrm{~h}$ of incubation at $37^{\circ} \mathrm{C}$ with agitation, the fluorescence was measured with a CytoflourTM 4000 plate-reading fluorometer (PerSeptive Biosystems, Inc., Farmington, MA, USA) as described [18]. The background fluorescence from mock transfected cells was subtracted from each reading to yield relative fluorescence units (RFU). Error bars on graphs of GFPspecific fluorescence represented the standard deviation of four wells from two individual transfections.

\section{Flow Cytometry}

Cells from a single well of a 12-well plate were recovered by centrifugation 3 days after transfection, resuspended in PBS, and analysed with a benchtop BD FACS Scan (BD Biosciences, San Jose, CA, USA).

\section{Results}

\section{PEI-DNA Uptake Assay}

To study the kinetics of PEI-DNA particle uptake in suspension-adapted $\mathrm{CHO}$ cells, it was first necessary to determine the linear range of reporter protein yield as a function of the amount of plasmid DNA transfected. Cells were transfected with various amounts of pEGFP-N1. The total amount of transfected DNA $(2.5 \mu \mathrm{g} /$ well $)$ was kept constant by addition of the appropriate amount of sheared salmon sperm DNA, and the PEI:DNA ratio was maintained at 2:1 (w/w). At 3 day post-transfection, the GFPspecific fluorescence increased linearly when the amount of pEGFP-N1 represented up to $2 \%$ of the transfected DNA 


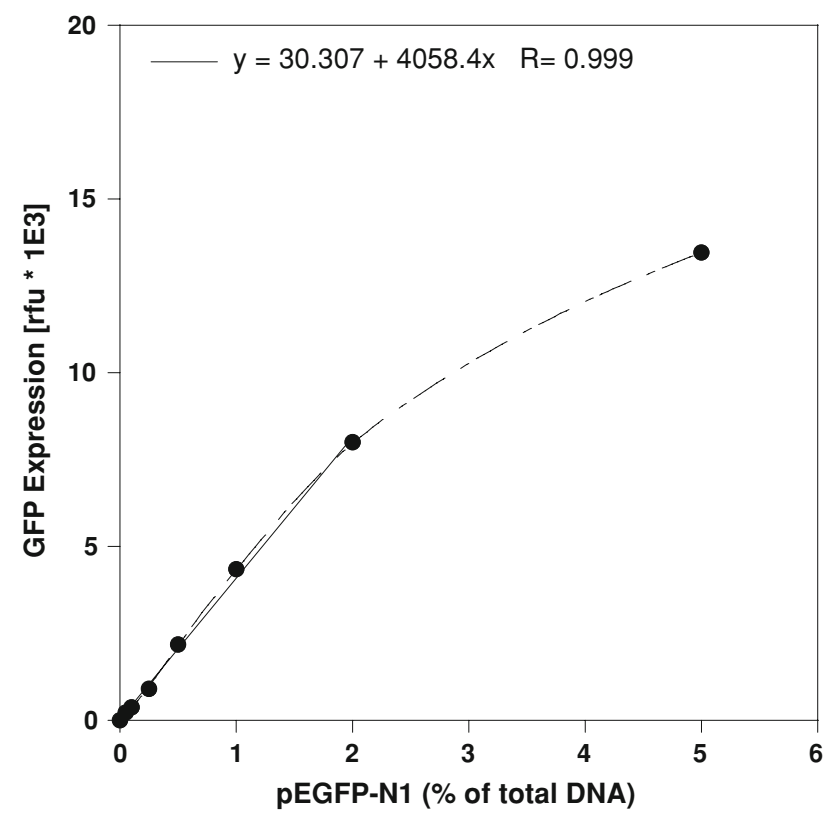

Fig. 1 Relationship between reporter plasmid quantity and transient reporter protein expression. CHO cells were transfected at a PEI:DNA ratio of 2:1 (w/w) with various amounts of pEGFP-N1 as indicated. The total amount of DNA was kept constant at $2.5 \mu \mathrm{g} / \mathrm{well}$ by addition of the appropriate amount of salmon sperm DNA. GFPspecific fluorescence was measured by fluorimetry at 3 day posttransfection and reported as relative fluorescence units (RFU)

(Fig. 1). Thereafter, cells were transfected with $2 \%$ pEGFP-N1 and 98\% salmon sperm DNA.

To efficiently arrest PEI-DNA particle uptake by cells, various amounts of competitor DNA (salmon sperm DNA or genomic DNA recovered from CHO cells) were added to cells immediately before transfection with pEGFP-N1 and salmon sperm DNA as described above. As the amount of competitor DNA increased, the GFP-specific fluorescence decreased (Fig. 2). With competitor DNA concentrations of $10 \mu \mathrm{g} / \mathrm{ml}$ or more, the GFP yield was reduced to $<0.2 \%$ of the control transfection. If the competitor DNA was added $3 \mathrm{~h}$ after transfection at a final concentration of $15 \mu \mathrm{g} / \mathrm{ml}$, no effect on GFP-specific fluorescence was observed relative to the transfection without competitor DNA (Fig. 2). The addition of competitor DNA did not have a negative effect on cell growth or viability (data not shown). For all subsequent experiments, salmon sperm DNA was used as the competitor DNA at a final concentration of $15 \mu \mathrm{g} / \mathrm{ml}$.

\section{Kinetics of PEI-DNA Uptake}

At various times after transfection with pEGFP-N1 and salmon sperm DNA, an excess of competitor DNA was added to the medium to inhibit PEI-DNA uptake. During the first $60 \mathrm{~min}$ after particle addition, a linear increase in

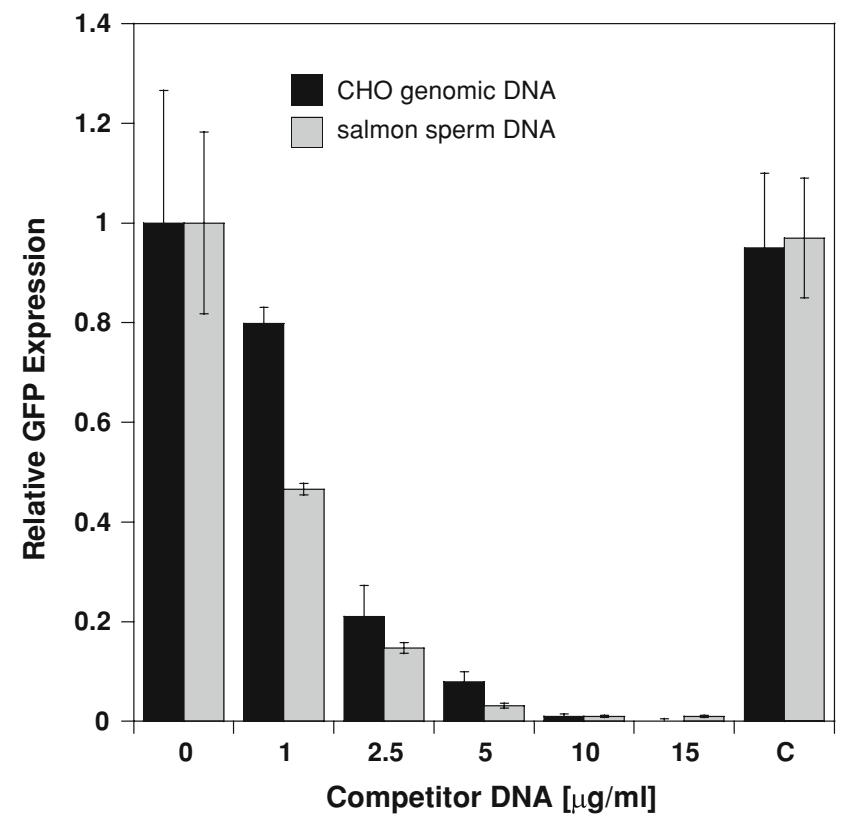

Fig. 2 Effect of competitor DNA on PEI-mediated transfection. Various amounts of salmon sperm or CHO genomic DNA were added to cells prior to transfection. The cells were then transfected with $2 \%$ pEGFP-N1 and 98\% salmon sperm DNA at a PEI:DNA ratio of 2:1 (w/w). As a control (C), the competitor DNA was added $3 \mathrm{~h}$ after transfection. GFP-specific fluorescence was measured by fluorimetry at 3 day post-transfection. The RFU values were normalized to the average value obtained for the transfections performed in the absence of competitor DNA

GFP-specific fluorescence was observed as the time before addition of competitor DNA increased (Fig. 3a). This pattern indicated a constant rate of particle uptake during the early phase of transfection. At later times of competitor DNA addition (1-3 $\mathrm{h}$ after particle addition), the rate of PEI-DNA uptake was reduced relative to the early phase (Fig. 3a). Despite the decrease in uptake rate, neither the PEI-DNA binding sites on the cell surface nor the endocytotic pathway were saturated since the cells were efficiently transfected with a different reporter plasmid 90 min after completion of the first transfection (data not shown). Similar results to those shown here were observed when IgG was the reporter protein (data not shown).

To determine if the inhibition of PEI-DNA uptake described above targeted a specific subset(s) of transfected cells, the competitor DNA was added to the culture medium at various times after transfection, and the cells were analyzed for GFP-specific fluorescence by flow cytometry after 3 days. The GFP-positive cells were arbitrarily divided into three categories corresponding to low, medium, and high levels of GFP-specific fluorescence (Fig. 3b). For each individual transfection, the number of cells in each category was determined and normalized to the number of cells in the same category of the control transfection in which the competitor DNA was added $3 \mathrm{~h}$ post-transfection. The 

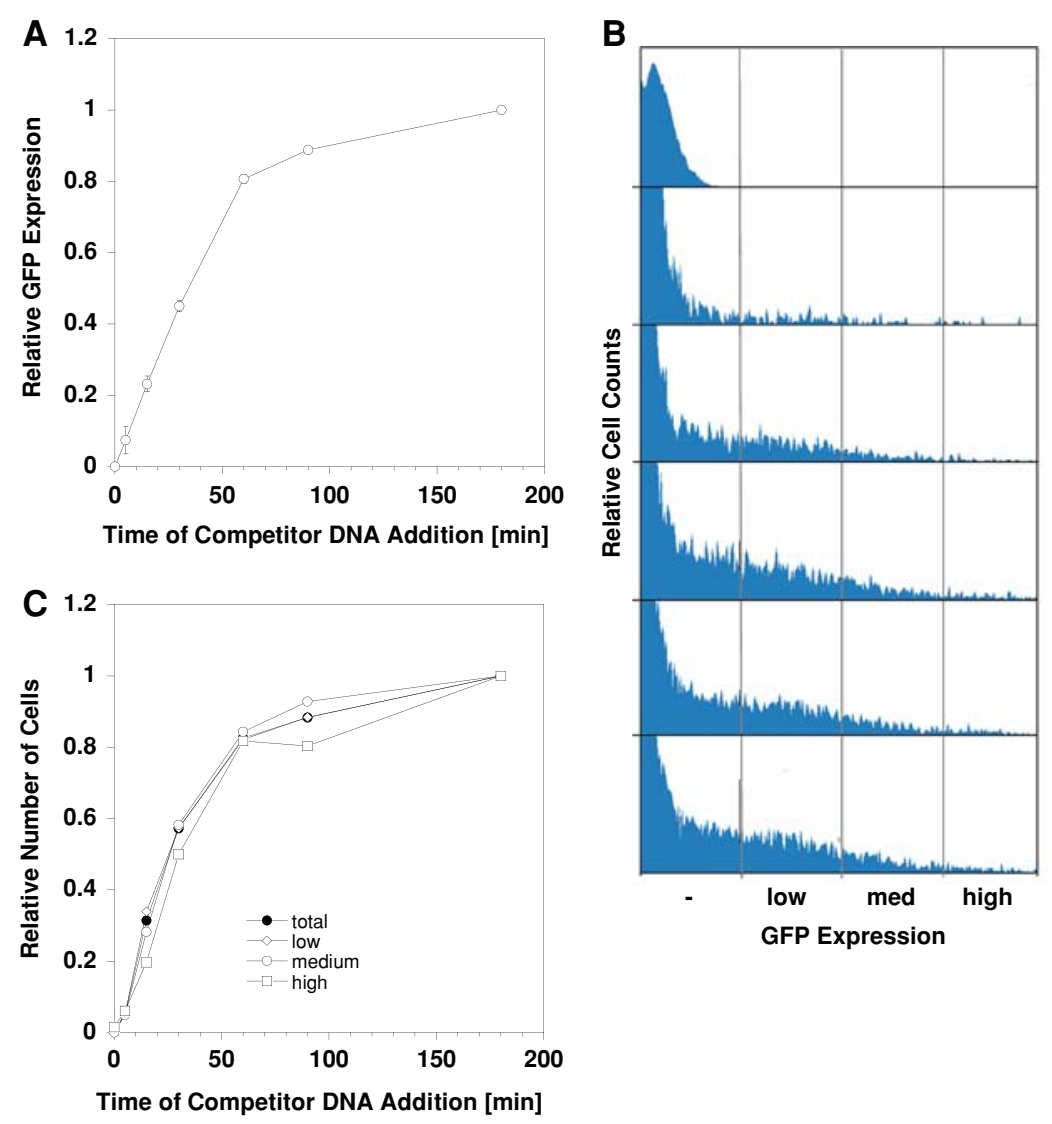

\section{Time of Competitor}

DNA Addition [min]

0

5

15

30

60

90
Fig. 3 Kinetics of PEI-DNA particle uptake. (a) Cells were transfected with $2 \%$ pEGFP-N1 and $98 \%$ salmon sperm DNA at a PEI:DNA ratio of $2: 1(\mathrm{w} / \mathrm{w})$. At the times indicated, salmon sperm DNA was added to the medium at a concentration of $15 \mu \mathrm{g} / \mathrm{ml}$. GFPspecific fluorescence was measured by fluorimetry at 3 day posttransfection. The RFU values were normalized to the average value obtained for the transfections in which the competitor DNA was added at $180 \mathrm{~min}$ post-transfection. (b) Cells were transfected as in (a) and the PEI-DNA uptake was inhibited at the times indicated by

normalized cell number for each category was then plotted versus the time of competitor DNA addition. The relative number of GFP-positive cells in each category was approximately the same regardless of the time of competitor DNA addition (Fig. 3c). This indicated that the assay was not dependent on inhibition of PEI-DNA uptake in a specific sub-population of transfected cells.

Effect of Particle Aggregation on the Kinetics of PEIDNA Uptake

The decrease in the rate of PEI-DNA uptake observed when the competitor DNA was added more than $1 \mathrm{~h}$ after the initiation of transfection suggested an effect of PEIDNA particle aggregation on the rate of uptake. To further investigate the effect of this parameter on the kinetics of PEI-DNA uptake, particles were formed at a PEI:DNA addition of salmon sperm DNA as in (a). The cells were analyzed for GFP-specific fluorescence at 3 day post-transfection by flow cytometry, and the GFP-positive cells were arbitrarily divided into three categories of fluorescence intensity (low, medium, and high). (c) The number of cells for each category described in (b) was normalized relative to the total number of cells in the same category from a control transfection in which the competitor DNA was added at $3 \mathrm{~h}$ post-transfection. The relative number of cells in each category was then plotted against the time of competitor DNA addition

ratio of 2:1 (w/w) by incubation at room temperature for different amounts of time before addition to cells. Competitor DNA was then added at various times after the start of transfection. At 3 day post-transfection, the highest level of GFP-specific fluorescence was observed for particles that had been incubated for $10 \mathrm{~min}$ prior to addition to cells (Fig. 4a). Not surprisingly, the rate of uptake during the early phase of transfection (first $60 \mathrm{~min}$ ) was greater for these particles than for those formed during incubations of 30 or 60 min (Fig. 4a). To determine if the cell culture medium itself had an inhibitory effect on particle maturation, PEI and DNA were allowed to incubate at room temperature for $10 \mathrm{~min}$ before dilution with $500 \mu \mathrm{l}$ of RPMI 1640. At various times afterward, the diluted particles were mixed with $500 \mu$ of RPMI 1640 with cells at a density of $4 \times 10^{6}$ cells $/ \mathrm{ml}$ in order to initiate transfection. For incubation times of $20 \mathrm{~min}$ or more in medium, the 


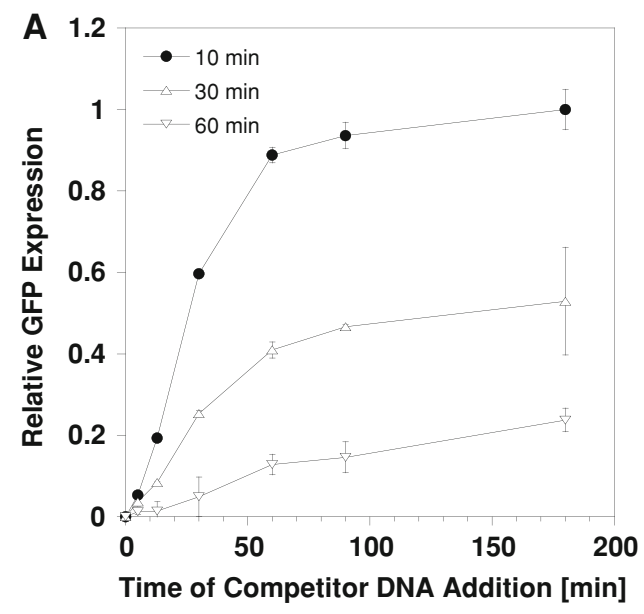

Fig. 4 Effect of particle maturation time on the kinetics of PEI-DNA uptake. Cells were transfected with $2 \%$ pEGFP-N1 and $98 \%$ salmon sperm DNA at a PEI:DNA ratio of 2:1 (w/w) after particle formation at room temperature for the times indicated. At various times thereafter, salmon sperm DNA was added to the medium at a concentration of $15 \mu \mathrm{g} / \mathrm{ml}$. GFP-specific fluorescence was measured by fluorimetry at 3 day post-transfection. The RFU values were normalized to the average value obtained for the transfection in which competitor DNA was added at $180 \mathrm{~min}$ post-transfection and the particle maturation time was $10 \mathrm{~min}$. (b) PEI-DNA particles formed

level of GFP-specific fluorescence was reduced in comparison with transfections performed with particles incubated in medium for $10 \mathrm{~min}$ or less (Fig. 4b). These results indicated that RPMI 1640 medium did not prevent PEI-DNA particle aggregation.

\section{Effect of PEI:DNA Ratio on the Kinetics of PEI-DNA Uptake}

After cells were transfected at different PEI:DNA ratios $(w / w)$, particle uptake was afterwards inhibited by competitor DNA addition at various times. The level of GFPspecific fluorescence and thus the rate of PEI-DNA uptake was approximately the same at PEI:DNA ratios of 2:1 to 6:1 (w/w) for the first 20 min of transfection (Fig. 5a). Within the next $10 \mathrm{~min}$, however, measurable differences in the rate of particle uptake were observed for the transfections at these PEI:DNA ratios (Fig. 5a). The variation in uptake rates resulted in different levels of GFP-specific fluorescence for these transfections with the highest level obtained at a PEI:DNA ratio of 2:1 (w/w). Interestingly, at a PEI:DNA ratio of 6:1 (w/w), PEI-DNA uptake was not observed following the first $30 \mathrm{~min}$ of transfection (Fig. 5a). At PEI:DNA ratios of 1:1 and 1.5:1 (w/w), the rates of PEI-DNA uptake within the first $20 \mathrm{~min}$ after particle addition were lower than for the transfection at a PEI:DNA ratio of 2:1 (Fig. 5a). The maximum levels of GFP-specific fluorescence for these transfections were also reduced relative to the transfection at a PEI:DNA ratio of

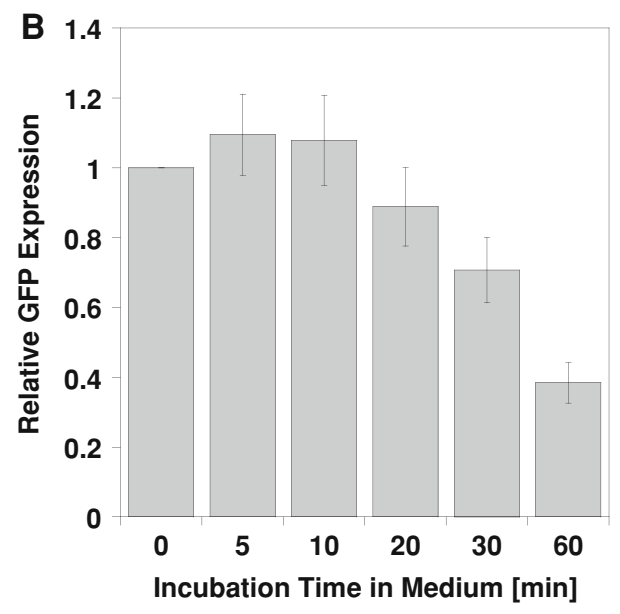

at a PEI:DNA ratio of 2:1 (w/w) by incubation at room temperature for $10 \mathrm{~min}$ were transferred to $500 \mu \mathrm{l}$ of fresh RPMI 1640 medium. After incubation for the times indicated, the solution was mixed with $500 \mu \mathrm{l}$ of cells at a density of $4 \times 10^{6}$ cells $/ \mathrm{ml}$ in RPMI 1640 to initiate transfection. After $3 \mathrm{~h}$, the cultures were diluted with one volume of ProCHO5 medium. GFP-specific fluorescence was measured by fluorimetry at 3 day post-transfection. The RFU values were normalized to the average value obtained for the transfections in which the PEI-DNA particles were not incubated in medium prior to addition to the cells

2:1 (Fig. 5a). Thus, the PEI:DNA ratio affected both the rate and extent of PEI-DNA uptake. Similar results were obtained when IgG was used as the reporter protein (data not shown). For all the transfections shown, the cell viability was nearly $100 \%$ at 3 day post-transfection regardless of the PEI:DNA ratio (data not shown). However, by 2 day post-transfection biomass accumulation was reduced as the amount of PEI increased, indicating an effect of PEI on cell growth and division (Fig. 5b).

\section{Effect of Cell Density on the Kinetics of PEI-DNA Uptake}

Cells seeded at different densities were transfected at a PEI:DNA ratio of 2:1 (w/w), and PEI-DNA uptake was inhibited at various times afterward by the addition of competitor DNA. Even within the first $10 \mathrm{~min}$ of transfection, measurable differences in the rates of PEI-DNA uptake were observed (Fig. 6a). Overall, the cell density at the time of transfection was found to be inversely related to the rate and extent of particle uptake (Fig. 6a). Similar results were obtained using $\operatorname{IgG}$ as the reporter protein (data not shown). To determine if the amount of PEI was the limiting factor for particle uptake in this experiment, cells at a density of $6 \times 10^{6}$ cells $/ \mathrm{ml}$ were transfected at various PEI:DNA ratios. At 3 day post-transfection, the highest level of GFP-specific fluorescence was observed at a PEI:DNA ratio of 5:1 (w/w) (Fig. 6b). By comparison, the optimal PEI:DNA ratio for transfection at a density of 


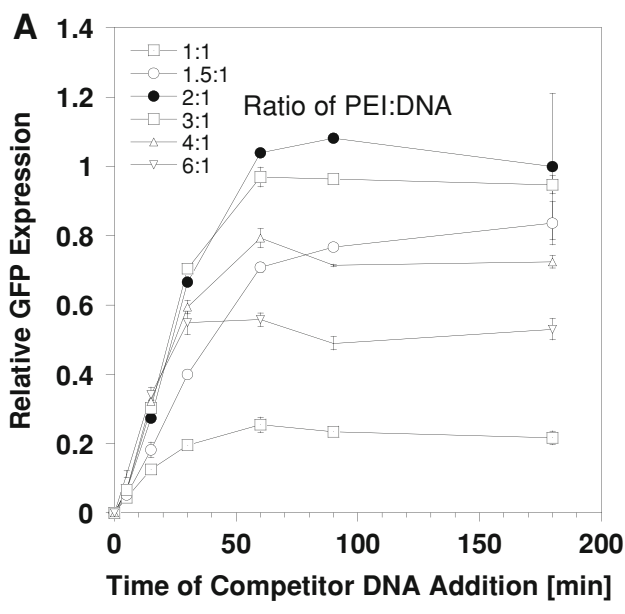

Fig. 5 Effect of PEI:DNA ratio on the kinetics of PEI-DNA uptake. (a) Cells were transfected with $2 \%$ pEGFP-N1 and $98 \%$ salmon sperm DNA at different PEI:DNA ratios as indicated by keeping the DNA amount constant and varying the amount of PEI. Salmon sperm DNA was added to the culture medium at a concentration of $15 \mu \mathrm{g} / \mathrm{ml}$ at the times indicated, and the GFP-specific fluorescence was measured by fluorimetry at 3 day post-transfection. The RFU values

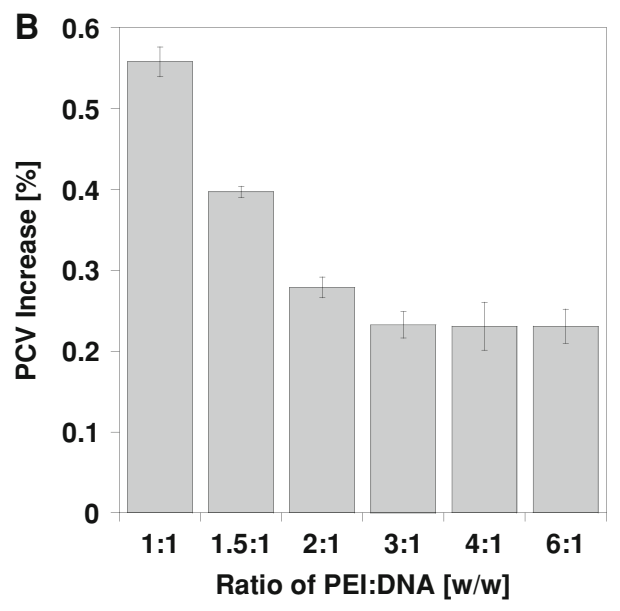

were normalized to the average value obtained for the transfections in which competitor DNA was added at $180 \mathrm{~min}$ post-transfection and the PEI:DNA ratio was 2:1. (b) The \% PCV of transfected cells was measured at the time of transfection and at 2 day post-transfection. The difference between the two values was plotted as a function of the PEI:DNA ratio used for transfection
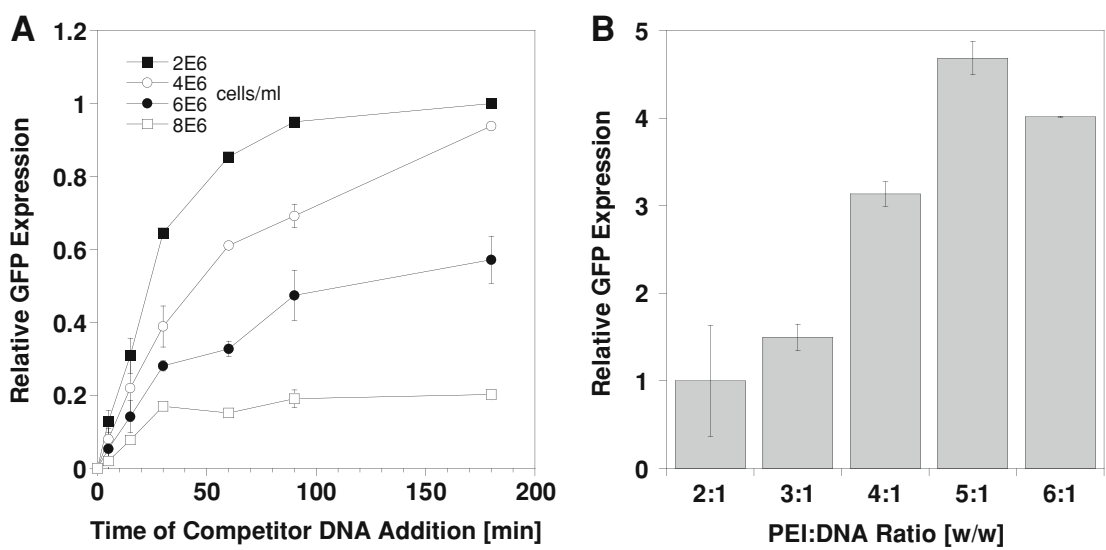

Fig. 6 Effect of cell density on the kinetics of PEI-DNA uptake. (a) Cells were seeded at different densities and transfected with $2 \%$ pEGFP-N1 and 98\% salmon sperm DNA at a PEI:DNA ratio of 2:1 (w/w). At the times indicated, salmon sperm DNA was added to the cultures at a concentration of $15 \mu \mathrm{g} / \mathrm{ml}$. GFP-specific fluorescence was measured by fluorimetry at 3 day post-transfection. The RFU values were normalized to the average value obtained for the transfections in which the competitor DNA was added at $180 \mathrm{~min}$ post-transfection and the cell density was $2 \times 10^{6}$ cells $/ \mathrm{ml}$. (b) Cells

$2 \times 10^{6}$ cells $/ \mathrm{ml}$ was $2: 1$ (w/w) (cf. Fig. $4 \mathrm{a}$ ). Thus, the effect of cell density on PEI-DNA uptake appeared to be due largely to a limitation in the amount of PEI present at the time of transfection since the reduction in GFP-specific fluorescence with increased cell density was overcome by transfection at a higher PEI:DNA ratio.

To further investigate the relationship between cell density and the amount of PEI, cells at different densities were transfected at a PEI:DNA ratio of 2:1 (w/w). At $3 \mathrm{~h}$ post-transfection, $2 \times 10^{6}$ cells were recovered by were seeded at a density of $6 \times 10^{6}$ cells $/ \mathrm{ml}$ and transfected as in (a) at various PEI:DNA ratios as indicated. GFP-specific fluorescence was measured as in (a). The RFU values were normalized to the average value obtained for the transfection at a PEI:DNA ratio of 2:1. (c) Cells were transfected as in (b) but no competitor DNA was added to the cultures. At $3 \mathrm{~h}$ post-transfection, the cultures were diluted with medium to $1 \times 10^{6}$ cells $/ \mathrm{ml}$. The $\%$ PCV was measured after dilution and 2 day later, and the increase in \% PCV was plotted against the density of cells at the time of transfection

centrifugation and resuspended in $2 \mathrm{ml}$ of a $1: 1(\mathrm{v} / \mathrm{v}) \mathrm{mix}$ of fresh RPMI 1640 and ProCHO5 CDM. The biomass was determined immediately after the medium change and then 2 days later. The change in biomass over 2 days was the highest for cells transfected at the highest cell densities (Fig. 6c). The differences observed in cell growth after replating in fresh medium may reflect the amount of PEI uptake during transfection with the cells at the lower densities accumulating more PEI and thus having a lower growth rate than those at the higher densities. 


\section{Discussion}

The addition of an excess of competitor DNA to cultures after the initiation of PEI-mediated transfection was shown to block PEI-DNA uptake. Using this approach, the kinetics of PEI-DNA uptake even at early times after transfection (60 min after PEI-DNA addition) were determined. Although the mechanism of inhibition was not fully investigated, it is thought that the competitor DNA caused the disassembly of preformed PEI-DNA particles or reduced the amount of free PEI (unbound to DNA) in the medium. As discussed in more detail below, the level of free PEI in the culture is critical for efficient PEI-DNA uptake by cells $[19,20]$. The addition of competitor DNA itself had no observable effect on cell growth and viability. Furthermore, no effect on reporter protein yield was detected if the competitor DNA was added at $3 \mathrm{~h}$ posttransfection. These results supported a direct effect of competitor DNA on PEI-DNA uptake.

The kinetic studies described here were performed under conditions in which the yield of reporter protein (GFP) increased linearly with the amount of reporter plasmid transfected. Therefore, the level of GFP-specific fluorescence measured at 3 day post-transfection reflected quantitatively the amount of PEI-DNA uptake. For transfections at a density of $2 \times 10^{6}$ cells/ml and a PEI:DNA ratio of $2: 1$ (w/w), about $80 \%$ of PEI-DNA uptake occurred within $60 \mathrm{~min}$ of the start of transfection. The rate of PEI-DNA uptake during this early phase of transfection was nearly constant, whereas the rate declined markedly during the subsequent $60 \mathrm{~min}$. The rate of uptake during the early phase was reduced by increasing the cell density at a constant PEI:DNA ratio or by increasing the PEI:DNA ratio at a constant cell density. These observations suggested that the balance between cell number and the amount of PEI transfected was the limiting factor during the early phase of transfection. The rapid uptake of PEIDNA within the first 60 min of transfection was surprising since others reported uptake only after cells were exposed to particles for $2 \mathrm{~h}$ [5]. Our results are supported, however, by the observation that complete endosomal turnover in CHO cells occurs within $30 \mathrm{~min}$ [21].

After the early phase of transfection, the aggregation of PEI-DNA particles appeared to be responsible for the decline in the rate of uptake. Particle aggregation has already been shown to be a limiting factor for the efficiency of transfection [8]. In our experiments both the rate and extent of PEI-DNA uptake decreased as the time of particle formation in either $150 \mathrm{mM} \mathrm{NaCl}$ or RPMI 1640 medium increased. Following $60 \mathrm{~min}$ of incubation under either of these conditions, the rate and extent of PEI-DNA uptake were 3-5 times lower than in the control transfection which followed $10 \mathrm{~min}$ of particle formation in $150 \mathrm{mM} \mathrm{NaCl}$.
Reduction of the salt concentration during particle formation has been shown to reduce the level of PEI-DNA aggregation in vitro [12]. Thus, conditions that restrict particle growth during transfection are expected to prolong the linear phase of particle uptake, resulting in higher levels of DNA delivery and recombinant protein production. It may be possible to achieve this by altering the composition of the culture medium used for transfection. In addition, we have recently demonstrated that separate addition of PEI and DNA directly to the culture enhances transient recombinant protein production in HEK 293 cells [22].

The cell density at the time of transfection and the PEI:DNA ratio are two other critical factors that determine the efficiency of PEI-mediated transfection. As mentioned above, these two parameters appeared to be interrelated. At a PEI:DNA ratio of 2:1 (w/w) both the rate and extent of particle uptake decreased with an increase in cell density. However, the increase in cell density was compensated by an increase in the PEI:DNA ratio. It has been shown that at PEI:DNA ratios yielding efficient transfection, the majority of PEI is not bound to DNA [23, 24]. Furthermore, as the PEI:DNA ratio increases, the quantity of PEI bound to DNA and therefore the particle's positive charge also increases [10]. The excess of bound PEI may enhance the efficiency of endosomal escape by PEI-DNA particles [19, $20,24]$. By increasing cell density while maintaining a constant PEI:DNA ratio it is expected that less PEI per cell will be internalized and the efficiency of transfection will be reduced. In contrast, by increasing the PEI:DNA ratio while maintaining a constant cell density, the uptake of an excess of PEI will have negative effects on transfection efficiency due to PEI's cytotoxicity.

Here the kinetics of PEI-DNA uptake in suspension cultures of $\mathrm{CHO}$ cells were determined for several key parameters necessary for efficient PEI-mediated transfection. These parameters included the time of particle formation, the PEI:DNA ratio, and the cell density. The effects of these parameters on the early kinetics of PEImediated transfection were demonstrated without the necessity of direct quantification of intracellular plasmid DNA. This approach is expected to be beneficial for further characterization of the limiting steps in PEI-mediated transfection for large-scale transient gene expression.

Acknowledgments We thank Dr. Lucia Baldi for critically reading the manuscript. Financial support was provided by the Swiss Innovation Promotion Agency (KTI/CTI).

\section{References}

1. Pham, P. L., Kamen, A., \& Durocher, Y. (2006). Large-scale transfection of mammalian cells for the fast production of recombinant proteins. Molecular Biotechnology, 34, 225-237. doi:10.1385/MB:34:2:225. 
2. Baldi, L., Hacker, D. L., Adam, M., \& Wurm, F. M. (2007). Recombinant protein production by large-scale transient gene expression in mammalian cells: State of the art and future perspectives. Biotechnological Letters, 29, 677-684. doi:10.1007/ s10529-006-9297-y.

3. Boussif, O., Lezoualc'h, F., Zanta, M. A., Mergny, M. D., Scherman, D., Demeneix, B., et al. (1995). A versatile vector for gene and oligonucleotide transfer into cells in culture and in vivo: Polyethylenimine. Proceedings of the National Academy of Sciences of the United States of America, 92, 7297-7301. doi: 10.1073/pnas.92.16.7297.

4. Pollard, H., Remy, J. S., Loussouarn, G., Demolombe, S., Behr, J. P., \& Escande, D. (1998). Polyethylenimine but not cationic lipids promotes transgene delivery to the nucleus in mammalian cells. Journal of Biological Chemistry, 273, 7507-7511. doi: 10.1074/jbc.273.13.7507.

5. Godbey, W. T., Wu, K. K., \& Mikos, A. G. (1999). Tracking the intracellular path of poly(ethylenimine)/DNA complexes for gene delivery. Proceedings of the National Academy of Sciences of the United States of America, 96, 5177-5181. doi:10.1073/pnas. 96.9.5177.

6. Godbey, W. T., Barry, M. A., Saggau, P., Wu, K. K., \& Mikos, A. G. (2000). Poly(ethylenimine)-mediated transfection: a new paradigm for gene delivery. Journal of Biomedical Materials Research, 51, 321-328. doi:10.1002/1097-4636(20000905)51: 3<321::AID-JBM5>3.0.CO;2-R.

7. Choosakoonkriang, S., Lobo, B. A., Koe, G. S., Koe, J. G., \& Middaugh, C. R. (2003). Biophysical characterization of PEI/ DNA complexes. Journal of Pharmaceutical Sciences, 92, 17101722. doi:10.1002/jps.10437.

8. Demeneix, B., \& Behr, J. P. (2005). Polyethylenimine (PEI). Advances in Genetics, 53, 217-230.

9. Akinc, A., Thomas, M., Klibanov, A., \& Langer, R. (2005). Exploring polyethylenime-mediated DNA transfection and the proton sponge hypothesis. Journal of Gene Medicine, 7, 657-663. doi:10.1002/jgm.696.

10. Bertschinger, M., Schertenleib, A., Backliwal, G., Jordan, M., Hacker, D. L., \& Wurm, F. M. (2006). Dissassembly of polyethylenimine-DNA particles in vitro: Implications for polyethylenimine-mediated DNA delivery. Journal of Controlled Release, 116, 96-104. doi:10.1016/j.jconrel.2006.09.006.

11. Thomas, M., Lu, J. J., Ge, Q., Zhang, C., Chen, J., \& Klibanov, A. M. (2005). Full deacylation of polyethylenimine dramatically boosts its gene delivery efficiency and specificity to mouse lung. Proceedings of the National Academy of Sciences of the United States of America, 102, 5679-5684. doi:10.1073/pnas.0502067102.

12. Wightman, L., Kircheis, R., Rossler, V., Carotta, S., Ruzicka, R., Kursa, M., et al. (2001). Different behavior of branched and linear polyethylenimine for gene delivery in vitro and in vivo. Journal of Gene Medicine, 3, 362-372. doi:10.1002/jgm.187.

13. Wurm, F., \& Bernard, A. (1999). Large-scale transient expression in mammalian cells for recombinant protein production. Current
Opinion in Biotechnology, 10, 156-159. doi:10.1016/S09581669(99)80027-5.

14. Bertschinger, M., Burki, C., Backliwal, G., Hacker, D. L., Jordan, M., \& Wurm, F. M. (2006). Polyethylenimine-based quality control assay for plasmid DNA. Analytical Biochemistry, 356, 309-311. doi:10.1016/j.ab.2006.05.002.

15. Muller, N., Girard, P., Hacker, D. L., Jordan, M., \& Wurm, F. M. (2005). Orbital shaker technology for the cultivation of mammalian cells in suspension. Biotechnology and Bioengineering, 89, 400-406. doi:10.1002/bit.20358.

16. Stettler, M., Jaccard, N., Hacker, D., DeJesus, M., Wurm, F. M., \& Jordan, M. (2006). New disposable tubes for rapid and precise biomass assessment for suspension cultures of mammalian cells. Biotechnology and Bioengineering, 95, 1228-1233. doi: 10.1002/bit.21071.

17. Derouazi, M., Girard, P., Van Tilborgh, F., Iglesias, K., Muller, N., Bertschinger, M., et al. (2004). Serum-free large-scale transient transfection of $\mathrm{CHO}$ cells. Biotechnology and Bioengineering, 87, 537-545. doi:10.1002/bit.20161.

18. Hunt, L., Jordan, M., DeJesus, M., \& Wurm, F. M. (1999). GFPexpressing mammalian cells for fast, sensitive, noninvasive cell growth assessment in a kinetic mode. Biotechnology and Bioengineering, 65, 201-205. doi:10.1002/(SICI)1097-0290(19991020) 65:2<201::AID-BIT10>3.0.CO;2-H.

19. Boeckle, S., von Gersdorff, K., van der Piepen, S., Culmsee, C., Wagner, E., \& Ogris, M. (2004). Purification of polyethylenimine polyplexes highlights the role of free polycations in gene transfer. Journal of Gene Medicine, 6, 1102-1111. doi:10.1002/jgm.598.

20. Kichler, A., Leborgne, C., Coeytaux, E., \& Danos, O. (2001). Polyethylenimine-mediated gene delivery: A mechanistic study. Journal of Gene Medicine, 3, 135-144. doi:10.1002/jgm.173.

21. Fujimoto, L. M., Roth, R., Heuser, J. E., \& Schmid, S. L. (2000). Actin assembly plays a variable, but not obligatory role in receptor-mediated endocytosis in mammalian cells. Traffic, 1, 161-171. doi:10.1034/j.1600-0854.2000.010208.x.

22. Backliwal, G., Hildinger, M., Hasija, V., \& Wurm, F. M. (2007). High-density transfection with HEK-293 cells allows doubling of transient titers and removes need for a priori DNA complex formation with PEI. Biotechnology and Bioengineering, 99, 721727. doi:10.1002/bit.21596.

23. Bertschinger, M., Chaboche, S., Jordan, M., \& Wurm, F. M. (2004). A spectrophotometric assay for the quantification of polyethylenimine in DNA nanoparticles. Analytical Biochemistry, 334, 196-198. doi:10.1016/j.ab.2004.07.020.

24. Clamme, J. P., Krishnamoorthy, G., \& Mely, Y. (2003). Intracellular dynamics of the gene delivery vehicle polyethylenimine during transfection: investigation by two-photon fluorescence correlation spectroscopy. Biochimica et Biophysica Acta, 1617, 52-61. doi:10.1016/j.bbamem.2003.09.002. 